\title{
PUBLIC ECONOMICS AS IF TIME MATTERS: CLIMATE CHANGE AND THE DYNAMICS OF POLICY ${ }^{1}$
}

Nicholas Stern

February 2018

\section{INTRODUCTION}

Tony Atkinson was one of the most thoughtful, creative, prolific and distinguished economists the world has seen. His deep humanity and decency, combined with his extraordinary intellectual ability, took him to the most important issues shaping the lives and livelihoods of people across the world, particularly the poorest. At the same time, he was constantly challenging and questioning, he never stopped asking whether the approaches we were using were capturing the essence of the crucial problems we were trying to tackle. He challenged our profession in the 1960 s by bringing, in his first book (Atkinson, 1969), poverty and individual circumstances in developed countries to centre stage in economics, in contrast to the aggregate, growth and class focus which was dominating so much of the discourse in our subject. And the intensity of his challenge to what economists do and how they do it continued to the last decade of his life, including in his 2015 book on inequality; indeed, in some ways it became still more intense.

This paper is an attempt, in part based on discussions with Tony, to articulate his agenda, and to add a little of my own, for public economics. It focuses on that fundamental part of the policy agenda which is about how change happens and what happens during change. It asks directly about the processes and pace of change. In other words, the task is the fostering or the creation of a genuinely dynamic public economics.

We had worked together on the Journal of Public Economics from its beginning in the 1970s (I was an editor with him for 17 years from 1981-1998, acting as a co-editor in the 1970s) and we never stopped discussing how public economics was faring and where it should go. I think his views on this crystallised and became stronger in recent years and I shall try to do justice to them. In doing so, I shall set out why a dynamic public economics matters so much, including and especially for a fundamental issue of our time, which Tony took extremely seriously, climate change.

The study of public economics has not, in its foundations, ignored processes of change but I think it is fair to say that they have been either on the margins or much less central than they should have been. Public economics should be about policy for beneficial change. The basic theoretical structure for our starting framework has been a static general equilibrium model which is designed to capture some problem or difficulty, which is identified and highlighted. The analysis then attempts to analyse and construct policy to manage or overcome the problem, as well as possible. This problem may be a market imperfection, externality or public good of the Pigou, Wicksell or Lindahl kind. Or it may be a constraint

\footnotetext{
${ }^{1}$ I am very grateful to Erzo Luttmer, editor, for helpful comments and to a referee who provided very constructive guidance. My greatest debt is to Tony Atkinson for a lifetime of interaction, collaboration, inspiration and friendship. The paper draws on my discussion with Tony of August 2016, published in the Annual Review of Economics, 2017.
} 
on information or tools available to the tax authorities, for example the inability to observe skill, which limits the ability to tax as, for example, in the models of Mirrlees, on income taxation; or the absence of lump-sum or income taxation in the models of Diamond and Mirrlees and others, following Ramsey, on commodity taxation. This was the great tradition of James Meade and it is valuable, focused and powerful. This standard approach is generally about the comparison of equilibrium outcomes under different policies, and not about how the change happens or how people are affected along the way, or indeed about how the process and pace of change during this policy transition influences what is possible in the future.

The standard approach has been extended to theories of reform, in other words the identification of improvements rather than optimality. Of course, the theory of optimality is embedded in the theory of reform; an optimum is a position from which there is no beneficial reform. James Meade, whom Tony knew well and enormously admired, was a key figure here, see particularly the mathematical appendix to his classic 1955 book on Trade and Welfare (see also, for example, Drèze and Stern, 1990; Guesnerie, 1977).

There is a different tradition which sees government failure as the pre-eminent difficulty and views the problem of public policy, in large measure, as being about getting the government out of the way so that the untrammelled market can do its job. It is argued that markets can and will perform the task of achieving efficiency and the fostering of initiative in a very effective, indeed in some sense optimal, way, provided the government plays a minimal role, confined to some basics, including the rule of law and security.

Both of these perspectives, and various combinations and variants, work mainly in terms of comparative statics; not exclusively but in large measure. We find two static equilibria, one with policy structure $A$, another with policy structure $B$, and policy $A$ is better than policy $B$ if the outcomes under $A$ are preferred to $B$ under some criterion (or criteria) for assessment.

For Tony there were many problems with this approach. As we shall see, the basic perfectly competitive structures troubled him when offered as a description of the world. So, too, did many of the criteria commonly used. And that, the main subject of this paper, the processes and pace of change played a minimal role. A comparison of end points in a process of change is, of course, of real value to policy assessment, public discussion and decisionmaking. But, we know that we cannot switch straight from one equilibrium to another, if indeed the challenge is about moving from one equilibrium to another. Further, what happens along the way can be of profound importance. Take one critical example, managing climate change. The phenomenon of global warming is associated with concentrations of greenhouse gases (GHGs) in the atmosphere, which inhibit the escape of infra-red energy and thus cause warming. These stocks or concentrations are a result of preceding flows, or emissions. Hence the path of emissions is critical. For two paths with the same emissions now and in 2050, one may yield much higher concentrations of GHGs in 2050 than another which reduces emissions later in the period between now and 2050. The path influences not only outcomes within the period but also beyond because, if the stock of concentrations is higher at the end, there will be more warming and climate change in the years to follow. Further, many of the damages to environment, natural capital and infrastructure will be difficult or impossible to reverse. 


\section{Some of Tony Atkinson's issues for public economics}

As a background or foundation for an examination of what is involved in building a dynamic public economics, let me draw on some of Tony's concerns with the standard modelling of, and approaches to, policy issues. These are based, first, on a one-hour structured discussion I had with Tony, on his life and work, in August 2016, published in the Annual Review of Economics in 2017 and, second, on the introduction to the new edition of Atkinson and Stiglitz, Lectures on Public Economics, 2015. Tony raised five issues in our August 2016 discussion.

\section{Subject matter or objectives}

We should, he argued, go beyond aggregates, such as growth or total or average income with undifferentiated individuals. And we should get more specific than generalised social welfare functions with their general, but unspecific, vectors of consumption. Further, these vectors are usually dependent only on own consumption. The generality has its usefulness but the lack of specificity loses focus on what matters. The narrow self-interest embodied in the restriction to own consumption is, on the other hand, far too restrictive. We should try to study the issues that do, or should, concern the lives and livelihoods of people, particularly those in difficult circumstances, and of those who will come later. For Tony, our subject matter should have at its core: poverty and inequality; living standards understood in specific ways such as food, shelter, health and education; environment and sustainability. These can be shoe-horned into the standard formulations, but often only in artificial and restrictive ways.

\section{Breadth}

Tony saw himself as an economist and not as one particular category; he argued that narrow self-labelling as, say, "a labour economist" or "industrial economist", potentially limited understanding. We should start with the issue and bring to it the analytical tools and perspectives it requires. That includes going beyond economics. He was a great example of the approaches that he advocated.

\section{Modelling}

Again, focus on the issues and questions. This may well imply that the perfectly competitive equilibrium is not the natural starting point. He was concerned both with the adjective, perfectly competitive, and with the noun, equilibrium. He saw examples of managers of firms pursuing narrow self-interest at the expense of owners, employees, consumers and society as a whole. He saw the destruction of assets and the corrosion of the social fabric in the UK in the 1980s as a damaging and unnecessary phenomenon arising from a policy, often termed 'market fundamentalism', whose motivations appeared to attach little importance to processes of change and what they might mean for the people involved.

\section{Political economy}

Policy formulation and design should analyse interests and mechanisms that might oppose policy reform. He spoke more and more of the purchase, by very powerful vested interests, of policy-makers and policy-making in, for example, the USA. 


\section{Process and pace of change}

For many key issues the process and pace of change will be absolutely central to shaping outcomes over time and people. And the process and pace will be influenced by the above four issues that Tony raised directly in our August 2016 discussion.

Tony Atkinson and Joe Stiglitz revisited the underlying assumptions and approaches of public economics, which they had adopted in their 1980 volume, which was designed to capture the then state-of-the-art. They expressed some of their concerns in their introduction to Lectures on Public Economics (2015), thirty-five years after the original publication. It is perhaps unsurprising that the experience, often difficult, of those years and the advance of economics during that period should give cause for reflection. The ensuing three and a half decades began with the years of the 1980s and early 1990s, the years of market fundamentalism, of antipathy towards redistribution and of the Reagan and Thatcher approach to the role of the state. These were years in which, as Tony put it, "I think we took a wrong turn" (Atkinson and Stern, 2017, p13).

Both Tony and I set out our concerns in print at the time (for example, Stern, 1991 and 1992; Atkinson, $1990^{2}$ ) but with little effect. It often felt as if many Anglo-Saxon economists were telling politicians what they wanted to hear, namely something along the lines of "we can always improve public policy by having both less of it and a smaller state", or "the more we leave things to the market, the better the outcomes will be." In large measure, this was mantra rather than careful analysis, although the political and economic history of the preceding decades do offer some understanding of how all this happened. It was, in large measure, an intense reaction to the expansion of the state embodied in the structures which were built in the two or three decades following the Second World War. This included public monopolies and powerful unions. No doubt reform was necessary; there was much that was dysfunctional and rigid. But the indiscriminate application of the mantra and the destructive outcomes for many troubled Tony. He was not alone.

There were some improvements in the rate of growth of productivity in the UK but there was much damage to our social and physical fabric in terms of our sense of community and mutual responsibility and to the state of our public places and assets; key parts of the economy went backwards and protracted unemployment destroyed human capital; and the seeds of the 2008 crisis were sewn in the ideology of deregulation ( there is good regulation and bad, but there was little effort to understand the difference). Whilst all that is a matter for another paper, it is important to recognise the significance of this period for the way in which Tony saw the world and the subject.

Some of Tony's reactions, together with Joe Stiglitz' reading of these events and of the role of the economics profession, are reflected in the new introduction to their text book as mentioned above.

\footnotetext{
2 Tony's piece entitled "Public Economics and the Economic Public" was mostly about how to communicate clearly and analytically in a quantitative way about the redistribution aspects of public policy, particularly taxation. It was motivated in large measure in reaction to those who wanted to marginalise redistributive policies.
} 
Not surprisingly, there is a strong overlap with the issues Tony raised in our August 2016 discussion. The first two of their concerns in their new introduction, however, have not been emphasised in our discussion so far: the integration of the world economy, which requires a much more global approach to policy; and the work of behavioural economics, The contributions of the latter have shown clearly the many and important inadequacies of the simple model of individual behaviour, in terms of its assumptions of clear and specific preferences, and full and immediate optimisation using all available information.

The internationalisation of the world economy was a remarkable and crucial feature of the three and a half decades between the two editions. The transmission of effects of policy in one country across the borders to many others cannot be ignored. Neither can the mobility of capital, firms and people. Issues of global public goods and externalities, such as climate, oceans, epidemics, security (cyber and otherwise), migration and so on have become much more prominent.

Behavioural economics has been one of the great advances in our subject in the last two or three decades. People appear to have what looks like multiple personae; for example, as Danny Kahneman (2013) put it "thinking fast and thinking slow" or impulsive and reflective. Another way of looking at this is to think of the higher self that, for example, commits to eating and drinking sensibly, and the lower self that might let go or binge. If we assume there is just one simple and consistent utility function, we can try to associate an increase in welfare of an individual with an increase in utility. When the ideas of behavioural economics are incorporated in our analyses, identifying increases in welfare is much less straightforward. Policy evaluation then appears to require the introduction of criteria beyond those derived from individual utility. That is something with which we must grapple. Amartya Sen's ideas of capability (Sen, 1999) or ideas of empowerment (Stern, Déthier and Rogers, 2005), which I have worked with and tried to develop, are ways of broadening and deepening the agenda which do not encounter the problems of the utilitywelfarist approach of standard public economics. Thus in evaluating or assessing, public policy we can ask how it opens up opportunities for people by enhancing, for example, health, education, purchasing power, or reducing negative discrimination.

\section{The example of climate change}

Climate change raises issues for economic analysis, and beyond economics, which are very broad and deep. We return to them in Sections 4 and 5 below and here describe only enough to motivate some of the general ideas on dynamics in public economics in Section 2 and on objectives and values in Section 3.

The greenhouse effect refers to the trapping, by the concentrations of GHGs in the atmosphere, of the infrared energy which is reflected from the surface of the earth. The trapping occurs though the oscillation of GHG molecules at a frequency that interferes with the infrared energy (it is thus the frequency of oscillation of the molecules which determines whether or not a gas is a GHG). Much of that concentration arises from the emissions of GHGs as a result of human activity, including from the burning of fossil fuels and from deforestation. The warming takes time to occur and the degree of warming and the consequential climate change and its effects are subject to uncertainty. Many of the 
effects come via water, or its absence, in some shape or form: storms, floods, inundation, drought and desertification, storm surges and sea-level rise, and so on.

This basic description of how the science works has fundamental consequences for economic modelling and the analysis and formulation of economic policy. This is a problem, the science tells us: (a) of public goods (it is the total across all sources of GHG concentrations that matter, and hence a problem where international collaboration is important); (b) of long-term effects but necessity for short-term action, (c) where, because of (b), values, both intergenerational and intragenerational, are key; and (d) where uncertainty and risk management are central in a context where risks are potentially immense.

Together, these have three consequences for the dynamic analysis of policy which is the main subject of this paper. First, urgency and scale. The world economy will likely roughly double in the next two decades or so (at a possible global growth rate of around 3\%). Infrastructure will more than double (see Bhattacharya et al, 2016). This will be in a period where we need to cut emissions, absolutely, by $20 \%$ to have a reasonable chance of holding temperature increases to $2^{\circ} \mathrm{C}$ (increase in average global surface temperature above the end of the $19^{\text {th }}$ century, the usual benchmark). On current trajectories, we risk eventual temperature increase of $3^{\circ} \mathrm{C}$ or $4^{\circ} \mathrm{C}$ or more, much of it during this century; we have not seen $3^{\circ} \mathrm{C}$ for around 3 million years. The dangers are potentially immense ${ }^{3}$ with possibly hundreds of millions or billions having to move, with likely severe and extended conflict as a consequence. And the reasons for movement and conflict could not simply be switched off. Cutting emissions by $20 \%$ absolutely, as the economy doubles in two decades, clearly demands action on pace and at scale. And analysis and action must recognise that if we follow old investment patterns, there is a serious risk of "lock-in" of high carbon, longlasting capital and infrastructure. As we shall note, taking action to change the nature of investments can be extremely attractive if we invest and plan well, including cities where we can move, breathe and prosper, but delivering these vitally important benefits does require strong and clear decision-making and substantial investment of the right kind.

Second, the rapid pace and large scale of change required imply that we must pay close attention to the processes of change. How can we understand and influence these processes so that we can foster change at the necessary pace and scale? We must ask questions not usually posed in a strong way in public economics: which forms of policy induce fast responses?

Third, given the long time scales involved and the intense importance for living standards, or indeed existence, of many in future generations, plus strong distributional issues occurring now, plus the importance of international action, our analysis must also pay close attention to values and social objectives. To promote agreement we must think through the origins of values and objectives and how they are formed and shared.

\footnotetext{
${ }^{3}$ The magnitude of the dangers associated with temperatures above $2^{\circ} \mathrm{C}$ are the reasons scientists have used this level of temperature increase as a marker of "dangerous climate change" and why the world set a target of "well below $2^{\circ} \mathrm{C}$ " in the landmark Paris agreement (COP21 of the UNFCCC) in December 2015.
} 
Given this agenda, the plan of the paper is as follows. In the next section, we look at the types of modelling for a constructive, dynamic public economics based on the concerns raised by Tony Atkinson and on the above issues which loom large in the questions posed by policy towards climate change. In Section 3, we examine the issues around social values and ethics, including discounting future outcomes and welfare. In Section 4 we look at the particular issues raised by climate change in modelling impacts and outcomes. In Section 5 we examine strategies and policies in relation to climate change, emphasising urgency, multiple market failures and infrastructure and including international action. In the concluding section, we go back to Tony's questions and see where our analysis points. Tony's questions, together with the deep issues raised by climate change, raise many major, subtle and difficulty analytical and modelling challenges. To anticipate the response that will emerge from examining the issues and questions: we should build a range of fairly simple but informative models focussing on the illumination of particular issues, rather than trying to build one grand all-encompassing model. The art of policy will be to come to a judgement and recommendations taking account of the range of models, the data available and the combination of qualitative and contextual circumstances that invariably surround important decision.

\section{TYPES OF MODEL: REAL DYNAMICS}

To claim that we should seek to build a new dynamic public economics should not be seen as negative or dismissive. Time has indeed been strongly present in much of the economic analysis of public policy, as I shall argue. The questions I am raising concern how deeply the role of time is captured, and the centrality of time in the core agenda, particularly concerning processes and pace of change. Much or most of our intertemporal analysis in public economics is equilibrium and much of it embodies theories of growth. There is a strong focus on the long run and steady states. What, I am arguing, we need more of is theorising about, and models that focus on, the following types of question: what happens in transitions; how does the path affect future possibilities; what are risks of extreme events; could there be extended traps, how radical change in real time can be fostered and managed; could instability arise and, if so, how and with what consequences; how long could processes take; who are likely gainers and losers during processes of change; and many more? I think it is fair to say that these types of questions are not generally at centre stage. They should be.

These are not questions which are greatly illuminated simply by saying that a good appearing at a different time is a different good and giving it a time index (although that is clearly a helpful convention). And they are not greatly illuminated by focusing on a comparison of end points at the beginning and end of change (although that can be relevant and interesting).

Such questions are of the essence in the economics of climate change, and some are examined below. But I hope it is clear that there are many other critical areas of our subject where such questions should also be central. Four obvious examples illustrate. The first concerns risks of financial crisis and the dynamics that might precede and follow, including gainers ex ante, and sufferers ex post. How fast and dramatic might such happenings be? How do the pressures build and for how long? What can happen to people during the 
intense period of crisis and the recovery that might follow? How slow might a recovery be, how does it occur, and what could the long-term effects be? There is surely much more we need to understand, for example, about the dynamics of the 2008 financial crisis, both before it occurred and in the difficult years that have followed.

A second example concerns the transition from one kind of economic structure or organisation to another. Of particular relevance in recent decades have been the transitions to market economies following the fall of the Berlin Wall and the radical changes in economic structures of the Soviet Union and Central and Eastern Europe. I was closely involved in some parts of the process, as Chief Economist of the European Bank for Reconstruction and Development (EBRD), which was established in 1991 to help facilitate and foster the transition. The process of transition was intense and of great importance; millions died in Russia of, it seems, stress-related causes. Long shadows were cast. In other countries, the process appears to have been less traumatic. China's transition has been very different and, on many dimensions, extraordinarily successful, although on other dimensions, including the environment and inequality, there have been some troubling features.

A third concerns economic transformation in wartime. In the UK in the second world war, ${ }^{4}$ for example, direct control of labour was used to get a thoroughly different set of goods and services produced. Timeliness was obviously of the essence. You would not as a guide to policy, introduce a reweighting in the social welfare function, and think about taxes that could lead you to a different allocation in equilibrium. That approach would not be wise. You would likely be over-run pretty quickly.

Fourth, technological transformation has been an area where economic historians such as Joseph Schumpeter, Chris Freeman and others have indeed been concerned with the process of transition and offer, in my view, good examples of how to formulate the right type of question. In "Reflections on Economics" (Besley, O'Donnell and Stern, 2015), Nick Crafts and David Soskice, both fine economists but also an economic historian and a political scientist, respectively, argue that an historical approach to growth and productivity carries powerful lessons about how and why change occurs. For all of these economists the causes and consequences of technological change constitute the central issue, but for all of them institutional structures are vital. Torsten Persson, in the same publication, emphasises strategic incentives in the policy-making process itself as core to modern institutional economies. For the "Austrian school" who examine markets as processes of discovery, and Friedrich Hayek (1988) and Hyman Minsky (1982), the processes of change, including expectations, the limits of understanding and how learning takes place, are of the essence.

Development economics should be about processes of change. The best of the literature does indeed focus on exactly this. Prime examples would be Arthur Lewis, Simon Kuznets, and Albert Hirschman. These are in strong contrast to Gunner Myrdal or Theodore Schultz, who saw poor societies in static equilibrium, although of rather contrasting kinds. At the core of the studies of Palanpur, a village in Moradabad District of Uttar Pradesh in India, on which I, with colleagues, have been researching for more than four decades, is the

\footnotetext{
${ }^{4}$ I use the example of my own country. Doubtless other countries at war, or moving into a period of war, have made rapid change too; when timing was critical.
} 
processes of economics change in the seven decades since India's independence. For the period 1950-1980, development was driven largely by technological change through investment in irrigation and the "green revolution" and, from 1980 onwards, by integration into the broader economy.

Hence we do see in economic history, in the study of technological change, in institutional economics and in development economics, excellent examples of a clear focus on processes of change.

But do we see the understanding of the processes of change at the heart of public economics? I would argue, not yet. Or at least not enough. Many of the work-horse models in the theory of taxation are in the tradition of the Diamond-Mirrlees framework for optimal commodity taxation (Diamond and Mirrlees, 1971). In optimal growth the possible paths are often dominated in their behaviour by the long-run steady-stage growth, to which the models are effectively limited by assumption..$^{5}$ There are, of course, useful examples and strands in public economics. We need many more. Let me indicate some such strands. Some have studied costs of transition to new policy-induced equilibrium (see e.g. Auerbach and Kotlikoff, 1987).

Second, Philippe Aghion and others (Aghion et al., 2012 and 2014) have shown the importance of "path dependence" in endogenous growth models. Third, there are studies of policy adaptation to "exogenous change" as a result of technical progress (Faulhaber, 2004; Hoppman et al., 2014; Ablon and Golay, 2017). A fourth, rarely studied, concerns models which are basically unstable and, for example, as in climate change, could involve catastrophic downward spirals, including large-scale loss of life. The example of climate change does involve all four, but particularly the last three.

There is also progress as outlined in the 2015 introduction to the new edition of "Lectures on Public Economics" by Tony Atkinson and Joe Stiglitz, as described above in terms of, for example, the implications of monopolistic markets and entry barriers for the taxation of capital. And see Joe Stiglitz' paper, with results on capital taxation, in this volume where he shows the importance of capital taxation as soon as one departs from key simple assumptions of the Diamond-Mirrlees framework.

Empirical work in public economics has become much more sophisticated in recent decades with huge advances in the availability of data, in computational power and empirical methods. I think it is reasonable to say, however, that whilst the analysis of the possible impact of policies is greatly improved, it is still dominated by empirical comparison of different equilibria, with and without the policy change whose effects we are trying to isolate.

With this background and assessment of what we need and how we have progressed, let me try to point to some of the elements of existing theoretical tool kits that can help us, always remembering that the careful historical analysis of what has happened in the past, can be full of insight into how change occurs. We look very briefly at six modelling issues or

\footnotetext{
${ }^{5}$ Both Tony and I worked on optimal taxation and optimal growth as young men.
} 
lines of argument concerning (i) non-linearities, (ii) expectations and confidence, (iii) innovation and entrepreneurship, (iv) endogenous growth, (v) investment, irreversibilities and sunk costs, and (vi) political economy. Each one could constitute a major area of analysis and it is not possible to do justice to them all in a part of one section of one paper. I shall try to say enough to show that they can provide valuable insight into important features of a real dynamics, "real" in the sense that they can illuminate: how processes over time work; where timing of outcomes through the playing out of processes matter; and how the sequencing and history along a path can affect future possibilities. I will restrict myself to one paragraph on each.

I hope that my four examples of areas where time and timing are of central importance (from financial crisis to Schumpeterian technological change), together with the six modelling issues just set out, show clearly the approaches I am suggesting. We should be building a number of small specific models which can capture key elements of the problem or processes. Policy recommendations come from assembling insights from a number of different models, each of which has relevance to key aspects of the questions and processes we face. This is, I take it, an approach similar in spirit to those suggested by Krugman (see, for example, his section "In Defence of Little Models" in Krugman, 2000) and Blanchard (2018) in macroeconomics.

What I am counselling against in public economics is the attempt to see everything to one grand model which tries to capture almost everything of relevance. And I am also counselling against trying to force a problem with strong and distinctive features into a standard work horse, e.g. a neoclassical growth model, where it obviously does not fit. Climate will illustrate.

\section{Non-linearities}

An early study of how non-linearities could produce interesting dynamics was provided by Kaldor in his 1940 Economic Journal paper, "A model of the trade cycle" (Kaldor, 1940) He saw macroeconomic equilibrium in a Keynesian model through the intersection of nonlinear savings and investment functions, both of which were related to output. He saw the two functions shifting over time. For example, after an extended period at a high output equilibrium, the investment function would gradually shift downwards as perceived investment opportunities started to be exhausted. A "high output" equilibrium embodying the equality of saving and investment would no longer be possible and there would then be a sudden shift downwards to a much lower equilibrium output. This is an example of multiple equilibria, but with a sudden and explained shift and fast movement from one to another as the viability of the upper equilibrium vanishes. It could be seen as an example of the famous quote often attributed to Rudi Dornbusch, "sometimes things take much longer than you thought they would, but then happen much faster than you thought they could."

\section{Expectations, confidence, animal spirits}

For Keynes, the expectations, confidence and animal spirits of investors were fundamental to the willingness to commit to investment, for him the driver of aggregate demand. He emphasised that they are very difficult to model formally but their key determinants and how they changed could be discussed explicitly. For Hayek and Minsky there could be moments or episodes when they changed dramatically, and confidence in the workings of 
the system could collapse. "Animal spirits" are central to the explanation of the origins of the 2007/8 financial crisis offered by Akerlof and Shiller (2008). They argue that this crisis, as so many previous crises, was shaped or determined by a period of overconfidence, followed by underconfidence. They analyse how the first develops, how it is punctured and the swift collapse. Again, this is real dynamics in the sense that I have defined. The processes involved are not easy to capture in formal models, and none of the above authors did so, but they can nevertheless be traced in a fairly convincing way.

\section{Innovation and entrepreneurship}

Outstanding examples here are Schumpeter and Hirschman. Schumpeter (1942): famously told his story of "creative destruction" and of waves of technological change in terms of monopolistic rents associated with special positions or technologies becoming targets for new ways of doing things, which "creatively" destroy the pre-existing condition and technologies. Hirschman (1958), in his theory of unbalanced growth, also places entrepreneurship and the possibilities of "early profits" at centre stage, but this time in an environment of developing countries. Hirschman's argument was that public policy should, for example, encourage investment that creates a demand for an important input so that entrepreneurship, in scarce supply in this argument, is channelled into the supply of that input in the confidence that strong demand is there. Again, we see examples of how changes occur, the importance of confidence and the processes that can generate them; in Hirschman's case the implications for public policy were very explicit. In Palanpur, a poor Indian village (see above), recognition of, and entrepreneurship in response to, changing opportunities in irrigation, new seed varieties and outside opportunities, have, in large measure, determined how and when lives and livelihoods have changed.

\section{Endogenous growth and learning}

Aghion et al. (2012 and 2014) have studied the learning in the process of investment, whereby both the investor and others learn from the experience of investment and from production. A public policy example that they examine contains the question of how clean technologies can be encouraged so that the economy sets off down a path of cost-reduction and learning for clean technologies.

\section{Investment, irreversibilities and sunk costs}

Dixit and Pindyck (1994) focus on the possibility of irreversibilities and sunk costs as playing a crucial role in the timing of investment. This is real dynamics in the sense that commitments involve outcomes that cannot easily be undone. Again, history matters, and the making of one's own history for the future by decisions now has a crucial influence on those decisions. Very early in the discussion of irreversibilities in the economics of climate change, they give this example explicitly (Chapter 12.3 "The timing of environmental policy").

\section{Political economy}

Entrenched positions can affect both the pace at which change is possible and the design of policy for that change. When the European Trading System for carbon emissions was introduced it "grandfathered" emissions rights for existing firms by giving them free emissions permits equal to their original emissions. It was argued that if they were forced to pay the full amount immediately, there would be costs of adjustment and political 
opposition on a substantial scale. Exxon Mobil and the Koch brothers, as Oreskes and her co-authors have argued (Oreskes and Supran, 2017; Oreskes and Conway, 2010), have invested considerable sums to try to prevent policy on climate change that they think would damage their interests. The ability to move at the necessary pace for avoiding dangerous climate change has been directly influenced. Some more climate policy issues follow in section 5 .

Each of the six examples has been treated very briefly and through just one or two examples of research. In each case, however, I hope enough has been said to show clearly how they can embody "real dynamics" of the kind I have defined.

\section{UNDERSTANDING OBJECTIVES}

The standard criterion for evaluating outcomes in public economics is a social welfare function (SWF). This is generally seen as a function of individual utility functions, which usually depend on a vector of own consumption. From the intertemporal perspective, the vector of own consumption can include future consumption by an individual and the relevant households can include those occurring in the future. Uncertainty is generally dealt with by taking expectations of the social welfare function (although short cuts such as extra discounting sometimes occur, see below in this section). This approach via an SWF is sometimes call welfarism. Utilitarianism (where utilities have some cardinal interpretation and the SWF is the sum of utilities) is a special case of welfarism.

However, this standard approach in public economics is not necessarily standard in public decision-making. In that decision-making the setting of goals and targets is common. That involves a discussion of the dimensions of concern (for example, elements of health or education) and an attempt to capture advance or regress on those dimensions through some form of calibration or measurement. A key example internationally is the Sustainable Development Goals (SDGs) agreed at the UN in September 2015 and the Paris climate change agreement of December 2015 (again, more on these below).

Further, the standard public economics approach, or welfarism, is rather a narrow approach within a much broader set of perspectives around ethics or moral philosophy. Welfarism is a special case of consequentialism, where actions or policies are judged solely in terms of their consequences, and various criteria can be brought to bear in relation to consequences. Tony Atkinson was much concerned with consequences for poverty and inequality but judgements over improvements on these dimensions do not necessarily derive from some overarching SWF of standard form (although in some cases and with some assumptions, they might be pressed into that form).

Beyond consequentialism there are several important ethical approaches in moral philosophy which have commanded wide attention. These include: contractarianism (for example, Rousseau, Rawls); Kantian approaches to moral imperatives; Aristotelian approaches to virtue; rights and liberties (for example, J.S. Mill, Isaiah Berlin); and others. They all have substance and potential traction in relation to public decision-making and structures. 
It is not possible here to provide an extensive discussion of key dynamic issues in relation to welfarism, targeting and broader ethical approaches. However, there are some important conclusions from a discussion of objectives in relation to dynamic public policy, which I shall try to draw out. We focus, in turn, on strategic targeting, discounting within the standard welfarism and, very briefly, broader approaches.

\section{Strategic targeting}

Governments often set targets or limits, such as maximum waiting times in accident and emergency rooms, or limits on alcohol in relation to driving or literacy and numeracy. They may set targets or limits for aggregates such as air or water pollution. The UK sets, under its climate change legislation, targets or budgets for aggregate GHG emissions for five-year periods at a time, within an overall target of reducing emissions by $80 \%$ between 1990 and 2050. A number of governments have set targets indicating that no hydrocarbon-powered vehicles can be sold after a certain date (including UK, India, France). They may set expenditure targets such as $2 \%$ of national income on defence, or $0.7 \%$ on aid.

International agreements set first the Millennium Development Goals (MDGs agreed in 2000) for 2015 and then (agreed in 2015) the Sustainable Development Goals (SDGs). The MDGs covered poverty, health, education, environment and gender issues. They were an important influence on international development policy in the first two decades of this century. ${ }^{6}$ The SDGs apply to all countries and were agreed by all countries. ${ }^{7}$ They extend the dimensions of the MDGs with a strong emphasis on sustainability (including goals for forests, oceans, cities, infrastructure) and include inequality and international collaboration.

Targeting may be an intuitive attempt to distil "optimal paths" from an overall implicit SWF combined with an implicit model of what is feasible. Making such modelling explicit rather than implicit could be helpful and have real value in trying to identify what targets "should be" and what are the key influences and assumptions influencing these conclusions. But making these models explicit can be an elusive or impossible task. Many of the relationships which are important may be difficult to capture, riddled with uncertainties, and refer to future changes which are unknown. For many of the key processes, there may be very limited relevant data. The inadequacy of our formal modelling capabilities for important issues where policy decisions cannot, or should not, be ducked may not inhibit people from "having a go". Perhaps they should. But we should be keenly aware that such attempts may point in misleading directions, particularly when social welfare functions might be difficult to agree and the constraints on feasibility are difficult to capture. Nevertheless, from this perspective, targeting could be seen as an heuristic or short-cut approach to capturing key outcomes that could have emerged from an optimisation approach.

A second perspective (see, e.g., Besley and Coate, REFS) is to see the targeted objective as having overriding importance in social values. Thus we might target "poverty reduction" as

\footnotetext{
${ }^{6}$ When I was Chief Economist of the World Bank (2000-2003), we led the World Development Report with statistics on the MDGs, and they were the key subject of my regular reporting to the Development Committee of the World Bank.

7193 countries at the UN in September 2015.
} 
our primary concern. That is one position, understandable in some circumstances or perspectives, although it can have its tensions with Pareto or welfarist criteria (see, e.g., Kaplow and Shavell, REFS).

However, I do not think we can see all, or indeed most, examples of targeting either of these two ways. Targeting can be a constructive way forward in taking political choices or indicating directions of change when there are conflicting perceptions of values and very uncertain economic or social structures; or indeed disagreements over the nature of the structures relevant for decision-making. Thus, targets are often the result of political compromises and of attempts to navigate or overcome obstacles to change, in the face of major challenges or risks. This is not necessarily an irrational approach, but rather a pragmatic and helpful response to visions of what should be done and how to get things done, where we seek a way forward but we vary in our values and analyses.

In such a context, decision-making is not optimisation by a single decision-maker in charge of the system he or she surveys. Further, we may not be able to be very specific about the risks we are trying to manage. Nevertheless, we may be able to understand enough to be clear that the potential risks are very large, enough to be clear that major efforts to avoid them are necessary, and enough to be clear on the basic sense of direction and initial actions that appear necessary and desirable.

Governments or groups might find it easier to agree on what are the key dimensions at issue (such as health or education as important elements of the MDGs and SDGs, or temperature in the case of the Paris COP21 agreement) than on the underlying values and modelling that might deliver some notion of an optimal policy. And they then might be able to agree roughly where we should aim along those dimensions. In these circumstances an attempt to force agreement on underlying values and models could undermine rather than facilitate agreement. There is more on this in relation to climate in Sections 4 and 5.

It is interesting from this perspective that, in the Declaration of Independence, the founding fathers of the USA saw "the following truths to be self-evident". They did not try to offer some underlying ethical justification. It is a very telling example of the idea that it is sometimes easier to agree on broad conclusions than on the detail of the arguments justifying those conclusions. The potential difficulty in agreeing on reasons, or underlying arguments, is illustrated by pointing to the potential arguments that might justify the "truths" in the Declaration. John Locke, the key influence it seems, on Thomas Jefferson, the main drafter, appealed in his political philosophy to an underlying state of nature and law of nature, involving both a Christian theological foundation and a view of what it meant to be human. Some have pointed to the influence on Jefferson of the moral philosophy of Francis Hutcheson and his doctrine of "moral sense, a faculty inherent in all human beings that no mere government could violate." (Ellis, 1998, p.67). For Bertrand Russell, writing in the mid$20^{\text {th }}$ century, the theological basis for the rights asserted by Locke was hard to accept. He pointed to the possibility of a social contractarian basis for Locke's natural rights (Russell, 1961, pp.604-607). Given an array of different possible foundations, the Founding Fathers might well have failed to agree on the argumentation for the truths, equalities and rights asserted. But they found clear and strong agreement on the assertions themselves. The dynamic consequences were profound. 


\section{Discounting}

How we value goods in the future in relation to goods now is clearly a quintessential intertemporal issue. I will discuss it briefly here within the standard welfarist approach making five simple points. They are basic and clear, in my view, but it is surprising how much of the economics literature on discounting, in the context of climate and elsewhere, has failed to grasp them.

As a useful reference point for the discussion of discounting, it may be helpful to have in front of us the Ramsey approach, after Frank Ramsey who in 1928 set out a formal mathematical analysis of savings choices. He analysed the allocation of consumption in an infinite horizon model where the objective is maximisation of an intertemporal utility sum or integral, and income that is not consumed goes to capital accumulation. He represented these choices as, in essence, balancing the cost of a consumption reduction now against the benefits the investment, which it enables, could bring. This approach is so widely used in economics that we can think of it as a, or the, "standard" approach. In my view, it can indeed provide one useful anchor or reference point for a discussion of discounting. I should emphasise that I think that some of the underlying issues around intertemporal values and choices become still more clear if we think more generally and fundamentally, as I shall argue below.

I should be clear at the outset of this discussion of discounting that my concerns are not primarily with the standard model, but the way it has been used. For example, value judgements are pushed into it without much discussion, or justification. And data on market rates are imported into the discussions when a little thought would show they have little relevance.

In this Ramsey formulation in simple form, the marginal utility of consumption at a point in time should, on an optimum path, be equal to the marginal utility of consumption in the future that the investment from a consumption reduction at time $t$ could generate. We think of the marginal utility of consumption as representing the value of an extra unit of the commodity at time $t$. If we normalise that value at unity for time zero then this value at time $t$ is the discount factor, the relative value of a unit at time $t$ in relation to a unit at time zero (see below). In continuous time and after rearranging and taking time derivatives of this condition, we have that the rate of fall of the marginal utility of consumption, in other words (see below) the discount rate (the proportional rate of fall of the discount factor), on the path under examination at that point of time, should be equal to the rate of return on investment. This is the Ramsey-rule. Ramsey set it out for a single-consumer choice problem but it can be extended easily to a welfarist model of social optimisation, with a changing population, where social choices are across generations.

More formally, we can write the objective or maximand in a one-good, continuous-time model as

$$
\int_{0}^{\infty} N u(C / N) e^{-\delta t} d t,
$$

where $\mathrm{C}$ is aggregate consumption, $\mathrm{N}$ is population, $\mathrm{C} / \mathrm{N}$ is consumption per head and $\delta$ is a pure-time discount rate (see below). The marginal utility of consumption is $u^{\prime} e-\delta t$ (the 
partial derivative of the maximand with respect to $\mathrm{C}$ ). The discount rate, at a given point in time, or rate of fall of the marginal utility of consumption at that time, becomes, where $\dot{u}^{\prime}$ is the time derivative of $u^{\prime}$,

$$
\left(-\dot{u}^{\prime} / u^{\prime}\right)+\delta \text {. }
$$

The Ramsey rule in this type of model is that this should be equal to the marginal product of capital $\left(f^{\prime}(k)\right.$ in the case of a constant returns to scale production function where output per head is $f(k)$ a function of capital per head). Our focus here is on discounting.

In this very simple case it is clear that the strength of discounting is given by the combination of two terms. The first depends on how rapidly consumption per head is changing, together with the form of utility function, $u($ ). If future generations are richer on a given path at time than now, we may choose to assign a lower value to an increment to their consumption at time relative to such an increase now. The second $(\delta)$ depends on how strongly one chooses to discount a future life irrespective of the consumption it might embody; if $\delta>0$, we are assigning ( $v i a e^{-\delta t}$ in the maximand) a lower value to a person simply because of the date of birth. Both elements clearly involve value judgements. The first also involves the rate of change of consumption, which depends on choices, constraints et cetera.

In this formulation, as noted, we would likely regard future increments to consumption as less valuable if future generations are richer, but we must emphasise that whether they are richer or not will depend on a whole range of choices; with unmanaged climate change, they may be poorer. Obviously, because they depend on levels and ratios of change of consumption, the discount factors and rates along a path are endogenous to the choices shaping the path.

This simple formulation is helpful as a first cut at thinking about consumption allocation in the context of welfare across generations. It is a formal representation of how to balance increments across generations. Its implications will depend on further assumptions, including on the structure of production and technical progress. A current generation, dictating on behalf of future generations, might choose to give up an extra unit of consumption for the benefit of future generations if, via the production process, the benefit is 'seen to be' sufficiently large. From the point of view of the analysis of inequality and intertemporal allocation across generations from a welfarist perspective of social choices, it describes one way of thinking about the "right amount" of inequality across generations. In this very simple case, if we assume capital is productive, the "right" answer to this ethical question is a consumption path that rises over time, taking advantage of the productivity of capital. This very simple case illustrates some of the arguments which follow. But the issues are more clear, in my view, if we express ourselves more generally and go back to the fundamentals and definitions.

\section{(i) Discounting: be clear on basic concept}

The value of an increment in a good in the future, relative to an increment now, is the discount factor $(\lambda)$ for that good at that time. The proportionate rate of fall of the discount factor $(-\dot{\lambda} / \lambda)$ is the discount rate for that good at that time; it clearly depends on both the good and the time. The primary focus in evaluations should be on the discount factor, as that is the relative valuation or key relative price at issue for valuing costs and benefits 
occurring in the future, relative to now. That is the subject at issue in the evaluation of a stream of costs and benefits.

Starting with the right concept for the question at hand, here the discount factor, makes it immediately clear that it will depend on the state of affairs at the time $t$ in the future. Unmanaged climate change could make the future very poor. In such circumstances we might place a very high value on extra goods at that time; in other words, there would be negative discounting in the sense that the discount factor would be greater than one. This argument makes clear also that the state of nature that could occur is of critical relevance. So, too, is the person or persons to whom increments may occur. Understanding the discounting concept properly makes it clear that using the language of "the discount rate" as if there is one given rate is a serious misunderstanding of the basic issues: it is, indeed, a mistake.

\section{(ii) Discounting is endogenous}

This approach makes it very clear that discounting (and the "discount rate") is endogenous to our decisions and that endogeneity is potentially fierce in the case of climate change. A discount rate cannot simply be imported as exogenous and outside the model. This is illustrated in the Ramsey formulation above. The level and rate of change of consumption at each point of time is part of the choice. Thus discounting is shaped by that choice. If we are on a path with rapidly rising consumption then discounting would likely be strong and an increment of consumption to those in the future would have considerably less value than an increment now. But bad policies in relation to climate change could lead those in the future to be much worse off than now.

\section{(iii) Separate discounting from the treatment of uncertainty}

Within the welfarist approach, uncertainty is most straightforwardly treated by making it explicit and building it into objective functions by, for example, taking expectations of a social welfare function (SWF) across different possible states. Adding something to the discount rate is valid as a short-cut only in a very special case where "the end of the world" is the first event in a Poisson process, and the SWF is a sum of future utilities; in that case, the weight on utility in a period in the future is the probability, $\exp (-\alpha t)$ of survival up to that point, where $\alpha$ is the Poisson parameter.

\section{(iv) The weakness of the case for "pure-time discounting"}

The issues of pure-time discounting can arrive when considering how to value a life in the future. It is essentially defined as, attaching a lower weight to a life in the future, which is otherwise identical to a life now, except that it is in the future. If the pure-time discount rate were $2 \%$ per annum for example, then a life starting 35 years in the future, but otherwise identical to a life now, has a value of one-half that of a life now. In this sense it is discrimination by date of birth. It cannot be justified by some notion of the future being better off than now; that would be a separate issue, we are assuming here for the purposes of ethical comparison that the two lives are identical, except for birth date. It is very difficult to find serious ethical arguments for this kind of discrimination.

One argument that we see in (iii) above is the probability of existence. But that could justify only a rather small discount rate. A mere $50 \%$ probability of survival for the world and its 
population for 35 years, as in the example of the preceding paragraph, would seem implausibly low. And in any case, that form of discounting is just shorthand for capturing one particular form of uncertainty and is not, as such, an ethical position. The underlying ethical position would be the utilitarian sum of utilities adjusted for the probability of survival, and the exponential form models the probability of survival.

Arrow et al ( 2013) have raised an issue concerning whether or not the absence of pure-time discounting would give rise to very high savings rates or, indeed, savings rates close to or at $100 \%$ in some optimal savings models. This assumption, it is suggested, would lead to conclusions that would appear to be very odd or unacceptable. Essentially the result arises because it would seem attractive to push consumption off into the future because there is no discounting of future utility and we might, in this model, get a positive return on a delay of consumption. But, in my view, this argument is unpersuasive. The "unpleasant" conclusion arises in one class of models with a number of embodied assumptions. It is a mistake to attribute the "perceived peculiarity" of the conclusion about high saving entirely to one specific assumption. In such models of optimal savings, the "peculiar conclusion" goes away if, for example, technical progress is introduced. Thus, one could argue that the peculiarity is the consequence of an absence of technological progress. When results are very sensitive to many elements of a special model it is unconvincing to "point the finger" at one particular assumption as the "culprit". It is especially troubling when that is then used to try to make an otherwise dubious ethical argument. Introducing pure-time discounting is an ethical statement with substantial consequences and with little in the way of foundations in ethics or moral philosophy. Such a strong assumption with dubious ethical validity cannot stand on one particular, and in my view misleading, interpretation of the workings of one particular type of savings model.

There is a related argument based on the work of Koopmans (1960) and Diamond (1965) which indicates that equal treatment across time is inconsistent with a complete Paretian ordering. The problem is similar in the sense that with the criterion of equal treatment we have potentially divergent future utility integrals and incomplete orderings. As Diamond makes clear (see Stern, 2015, p.169) that result, based fundamentally on infinite horizons, is not a reason for introducing an otherwise unacceptably discriminatory criterion into the real-world finite horizon choices we must make.

Value judgements are value judgements, but that does not mean that rational arguments cannot or should not be brought to the table. Pure assertion is not enough. Such rational arguments are largely absent, in my view, in any serious justification of pure-time discounting. For further discussion, see Stern (2015, Chapter 5).

\section{(v) Discount rates for ethical evaluations cannot be read off from markets}

Market prices and interest rates, or rates of return, do not give us ethical evaluations - they are outcomes (equilibrium or otherwise) of the individual choices of many players. They do not even give individual marginal valuations where there are many market imperfections. And where there are many imperfections and many markets, there will be many market prices. This is simply not a viable route to the social evaluations that are necessary here.

\section{Beyond welfarism}


The welfarist approach of most public economics is just one way of looking at the ethics of public and private decision-making. There are several other approaches which command attention. These include the approaches of contractarianism, Kant, Aristotle, rights and liberty, and others. This is not the place for a detailed discussion; some elements of such a discussion are provided in Stern (2015, Chapter 6 and Stern, 2014).

We note simply here that all four of these perspectives or approaches that go beyond welfarism would seem to point to strong action on climate change. A contractarian approach would likely see riding roughshod over future lives by refusing to manage climate change as outside a reasonable or acceptable social contract. A Kantian categorical imperative is to behave as you would have others behave, and that would likely involve respecting the livelihoods of others. Similarly, a notion of virtue would likely exclude serious damage to the lives of others in pursuit of narrow self-interest. A rights approach would surely involve respect for the rights of future generation. These arguments are elaborated in Chapter 6 of Stern (2015) and in Stern (2014), which also provide references to further discussion of these perspectives.

Finally, we should emphasise that the issues of values loom so strongly in climate change that we must examine them directly. The value judgements are of such direct importance that they must be discussed and scrutinised directly. They cannot be reached down from some shelf without discussion or examination.

This section has been, in some ways, a bridge between the fairly general discussion of public economics and one specific but important example, climate change. For both the general and specific discussions, intertemporal values are at centre stage and explicit and careful discussion is crucial. Sadly, such discussion is often absent, implicit or careless.

\section{Climate change: the modelling}

Growth and technical progress, risk, and environment have long been rich and productive elements of our discipline and all three have been part of public economics. Generally, of course not always, the three areas are analysed separately in order to focus. But climate change inevitably involves all three and a dynamic public economics relevant to climate change must embody all three. It should be clear at the outset that attempting to handle all three in one overall model carries the dangers of oversimplifying on each of the three elements to the point where the overarching model is grossly misleading.

Unfortunately, that is what has happened in the standard modelling of climate change in the "Integrated Assessment Models" (IAMs) which have played a dominant role from the beginning of this literature and the early work of Cline (1992) and Nordhaus (1991) about a quarter of a century ago. That initial modelling was of real value but the subject has got stuck with a standard framework which, far from capturing the key elements of the story, actually leaves them out. On the damage side, in the standard framework, there is systematic and gross underestimation of risks from unmanaged climate change. And, on the action and opportunity side, it generally fails to describe both the potential lock-in effects of bad investment (via long-lasting high-carbon infrastructure, for example) and the 
great potential from fostering and investing in changing technology and economic organisation.

A standard IAM has a simple underlying growth story with, in many cases, an exogenous growth or savings rate. In the models, economic activity involves emissions which cumulate and cause temperature increase. In these models the effects of temperature increase are generally to damage only current output, and nothing else. Risk is treated in a summary way, often simply by putting in expected values (or mean equivalents). Outputs can be consumed, invested or spent on reducing emissions to mitigate climate change. There are production relationships describing the generation of output and the costs of reducing emissions. These models try to pose and to address the question of how much to divert potential investment that could increase output towards emissions reduction, that is to mitigation of climate change. Thus the title of Nordhaus' important and early piece (1992) was, "To slow or not to slow".

In attempting to build a model of growth, risk and environment, the modellers have been well-intentioned. But in doing so, they have so simplified each element as to, in large measure, render the models incapable of addressing the real questions that face us. Risks are portrayed as modest, affecting only current outputs and with no structural impacts on underlying growth. The technology in the standard framework for reducing emissions involves little or no learning and has diminishing returns to scale, thus rising marginal costs of action. What has happened in this approach to modelling is essentially an attempt to shoe-horn a new and immense problem into a narrow and familiar structure (essentially marginal perturbations within a standard growth model) using standard tools. It has not worked.

When facing an issue with risks of a potential magnitude very different from what we have experienced hitherto, we should begin with an attempt to understand the drivers of the problem, the science. And we must also think deeply about scale and dynamics in analysing potential responses, and here technology and economic organisation are fundamental. We comment briefly on the risks and the technologies in relation to past modelling attempts and to potential ways forward.

The form of the impact of climate change in standard IAM models is only usually via a multiplier on current output which depends on current temperature. ${ }^{8}$ There is no structural effect on growth rates - and no damage to capital. We have not seen $3^{\circ} \mathrm{C}$ for 3 million years and $4^{\circ}$ or $5^{\circ} \mathrm{C}$ for tens of millions of years. On current paths there are serious risks of such temperatures over the next century or so. Many areas would be submerged, others desertified, others battered by hurricanes and storms way beyond the intensity we now see. Hundreds of millions, possibly billions, of people would have to move. Such transformations would surely involve radical change in what growth is possible and devastating damage to physical, natural, human and social capital. We cannot be precise about exactly when and where this could happen but climate science and climate history tells us that these risks are potentially immense and real and that it would be reckless to act as if those risks are small. The nature and magnitude of these risks is what drives rational concern about climate,

\footnotetext{
${ }^{8}$ Sometimes a non-multiplicative form is used, but generally the modelling of output loss is a function of current temperature and current output.
} 
based on the science, but the economic models largely leave out key risks that the science suggests are possible (i.e. disturbance or destruction of growth and capital, mass population movement and so on). Many scientists are deeply puzzled, indeed very anxious, about such modelling and the complacency it appears to generate amongst some economists in relation to appropriate action.

It is not just the structural defects and omissions of risks in the modelling as just described that are troubling. It is also the assumed magnitude of damages built into the economic models. Most models have damages from a $4^{\circ}$ or $5^{\circ} \mathrm{C}$ increase around 5 or $10 \%$ of current output (see Nordhaus, 2013). Some Nordhaus models have only a $50 \%$ drop in output at $18^{\circ} \mathrm{C}$ temperature increase. Human life would likely be extinguished on the planet at far lower temperatures than that. Many models, for example Tol (2012), have damages far less than this.

These numbers in these models are just astonishingly small in the context of climate history. Such temperatures, 4 or $5^{\circ} \mathrm{C}$ and upwards, not experienced probably for 30 or more million years, would involve a planet very different from the one we now see; they could arrive in the next century or so, extremely rapidly in terms of climate history. Lives and livelihoods would likely be destroyed across the globe. We do not know how to model such transitions and transformations very precisely: they are so far beyond human experience. But an estimate of damages in terms of a potential loss of 5 or $10 \%$ of output seems to be extraordinarily small. For example, the carrying capacity of population on the planet could likely be far lower than the 10 billion or so anticipated in standard demographic projections over a century or more (United Nations Environment Programme, 2012). We are potentially speaking of loss of life on a very large scale.

These formulations generally arise from grossly simplistic econometrics or applied economics. Broadly speaking, there have been two "econometric" routes in the literature, neither of which makes much sense. I simplify here, but most attempts to "calibrate damages" fit into one of these forms in terms of basic approach (or some combination). The "intertemporal estimation" route looks back over the experience since temperatures started increasing with the strong build-up of hydrocarbon-fuelled growth; this period is mostly post-Second World War. Temperature ranges might be $0^{\circ}-1^{\circ} \mathrm{C}$ or $0.5^{\circ}-1^{\circ} \mathrm{C}$. It is very hard to argue that there is information in temperatures over that range which can help us in understanding increases of $3^{\circ}, 4^{\circ}$ or $5^{\circ} \mathrm{C}$. It is only by extrapolation in a structure where the functional form for the extrapolation plays an overwhelming role that can one use $0-1^{\circ} \mathrm{C}$ as a basis for estimating impacts for $3-5^{\circ} \mathrm{C}$. But it is surely implausible that experience over $0-1^{\circ} \mathrm{C}$ can tell us very much about the curvature of the functional form that is so critical to such extrapolations. We have to look elsewhere for the relevant evidence, in part in the very long-term climate history that can provide some guidance as to what a $3-5^{\circ} \mathrm{C}$ world might look like. But beyond that we also have to think of the potential traumas of the transition; this is climate change at an historically rapid rate and not just a comparison between equilibria at different global temperature.

The second way of estimating, tried by some of those thinking about quantifying potential climate damages, is to compare productivity or welfare in places at different temperatures; that is a cross-section approach. But that is also deeply implausible as a method of 
capturing global effects in the sense that the difference in temperature between, say, Stockholm and Madrid is a very different matter from a major global temperature increase. Damage from climate change is mostly about water, or its absence, in some shape or form: storms, floods, droughts, sea-level rise, and so on. These effects involve the functioning of the global climate systems as a whole, and local climate impacts from such global temperature increase are very poorly captured by local temperatures. The examples of hurricanes and tropical storms, or the potential desertification of southern Europe, illustrate the point.

The first econometric approach involves, as argued above, grossly misleading projecting outside sample. The second attempts to link contemporaneous temperature difference within a given global climate to the different global climates that could arise with different and much higher temperatures in the future. That is to misunderstand climate science and the meaning of global climate change. Neither approach constitutes use of evidence that is remotely plausible. Having said that, the second approach carries some interest, for example, on adaptation to temperature difference at different locations. But is does not tell us much about global climate change.

This is not, of course, an argument against the use of evidence. It is an argument against the use of evidence that is based on data with only a minimal or spurious relevance to the problem at hand. More relevant is the long-run evidence on the state of the world when it was, say, 3 or 4. Centigrade higher than now, perhaps 3 million or tens of millions years ago. Or higher temperatures when we have to go back many tens of millions of years. However, we do know many relevant things from these data, including sea levels (tens of metres higher than now), where deserts were, or were not, and where mammals could live, and so on. Enough to be clear that there would be radical change in populations that could be supported and where they could live. We know major climate change has produced major extinctions.

We also know something of the physics of the strength of hurricanes and sea temperatures and the consequences of more intense hurricanes. We can try to model the consequences for river flows, of radical changes in snows and glaciers of the Himalayas or the Andes. There is much evidence that we can use which does offer insight into global risks.

This is the relevant evidence and it suggests the real possibility of catastrophic damage to human well-being. It is simply not reflected in the models. ${ }^{9}$ Some research is beginning to emerge which is more analytically relevant and serious on quantifying possible damages (see, for example, the work of Michael Greenstone at the Climate Lab in Chicago, and Ottmar Edenhofer at the Potsdam Institute).

The modelling of the production side in most IAMs is also deeply troubling. We have seen immense advances in technology and learning in the relatively short period when we have begun to focus on the practicalities of a transition to low or zero-carbon growth. The price of a solar panel has fallen by a factor of 10 or more in a decade. Costs have fallen rapidly in on-shore and off-shore wind. There have been great advances in storage of energy. There

\footnotetext{
${ }^{9}$ See also Pindyck, 2013, on the lack of credibility of this type of climate modelling.
} 
are likely more on the way in renewables and storage. In the last decade, there have been huge advances in hybrid and electric cars to the point that there is recognition by car makers and policy makers that the era of mass sales of vehicles incorporating the internal combustion engine has only 2 or 3 decades further to run. The digital and artificial intelligence management of energy demand and supply has enormous potential, and is moving very rapidly. So, too, the transmission networks and linking of grids. We can now see the tremendous potential in organising our cities in ways that enable us to move, breathe, and prosper. The potential in energy and resource efficiency and productivity is immense; there have been many advances and there are more on the way. We are learning much more about capturing carbon in soils and forests and making progress in methods for direct capture of carbon and its use or storage. We will have to understand much more about managing and protecting oceans but again work is underway.

This is an area where we can now see the huge potential of dynamic increasing returns in technological change, and the potentially huge returns from better physical and economic design and organisation. By making something a priority, such as efficiency or low-carbon, by public discussion, by pricing and taxing, by regulating, by $R$ and $D$ investment, by city planning or land management, and so on, we can generate remarkable technical creativity and progress. And we learn enormously along the way. A key task of dynamic public economics is to understand how to foster such processes. We should be very clear that static cost functions with diminishing returns to scale and rising marginal costs are grossly misleading, in the contexts of the cost structures we have been describing and on how they are changing.

There is another fundamental technological issue, on both the production and consumption sides of economic activity, and that is "lock-in". Infrastructure and capital, once invested, 'lock-in' the use of key inputs, in particular hydrocarbons. The capital can last for many decades - for example, coal-fired power stations. The same is true of, although often for only a decade or two, of consumer durables, such as cars. Thus there can be major costs of delay.

This is not the place to further develop these arguments on the failures of IAMs, the most prominent tool in the economics of climate change; for an elaboration, see Stern 2015, Chapter 4. The purpose here has been to show what is involved in the modelling side of a dynamic public economics. The dynamics here are of a fundamental kind. Damages from unmanaged climate change are potentially immense, result from an integral of emissions, occur across the whole economic and physical system and, in many ways, are potentially long-lasting or irreversible. The economic response has to be very large, involve dynamic increasing returns, changed economic and urban organisation and design, and the avoidance of potential lock-ins. Yet we have seen models predominate where these elements, the guts of the story, are essentially assumed away. That cannot be a dynamic public economics of the kind the problem demands.

We need a new generation of economic models which do embody the characteristics we have described. Given the nature and subtleties of each element, it is unlikely to be a good analytical or modelling strategy to try to build them all into one grand model. But we can model dynamic increasing returns (see, for example, Aghion et al 2014) and we can model 
irreversibility in investment in the context of uncertainty (see, for example, Dixit and Pindyck, 1994). We have the beginnings of the modelling of extreme risk in the work of Weitzman (2011). Thus, we can see the beginnings of very good theory, or sets of theories and models, which capture key elements. We need more of it.

At the same time, we have to make policy, now. We have seen that the next twenty years are decisive (Section 1) and that delay is dangerous. Thus we need to think how to make best use of what we now know, or think we know or understand. We need an applied economics of policy that puts argument and perspectives together based on current understandings, models, theories, evidence and judgement. Decisions now should provide structural guidance at the same time as we invest further in empirical and theoretical understanding.

To illustrate, let me point to the work on the New Climate Economy from the Global Commission on the Economy and Climate which I co-chair. We showed in our work, "Better Growth, Better Climate" (2014) and in "The Sustainable Infrastructure Imperative" (2016) how a well-designed transition to a low or zero-carbon economy could proceed over the next two decades. We showed that we could indeed generate both better growth and better climate and that sustainable infrastructure was at its core. The better growth comes from a much less polluted and congested form of living, particularly in our cities, and from a much less destructive approach to our land, forests and oceans. It can be growth that is strong, sustainable and much more attractive. It will involve radical change in the way we foster and finance infrastructure. Meeting the Paris COP21 targets of "well-below $2^{\circ} \mathrm{C}$ " involves almost all infrastructure investment being sustainable from now on. That in turn requires good economic policy and well-structured finance. It is to policy that we now turn.

\section{Climate CHANGE: THE POLICIES}

A dynamic public economics for climate change must set policies in the context of a strategy that takes careful account of the medium and longer term and associated risks and of the urgency of the necessary action; it must examine prices and incentives; and it must describe how sustainable investment can be fostered and financed. We take these three in turn. We then comment briefly on the principles, practicalities and dynamics of the formation of international agreements and objectives for responding to a challenge that embodies what is quintessentially a global public good and, in particular, on the important example of the construction of the Paris agreement at UNFCCC COP21, Paris, December 2015 and on the delivery of the agenda it set.

\section{Strategy and policy}

We have described global strategic objectives in terms of the Paris target of well below $2^{\circ} \mathrm{C}$ and the UN SDGs. For a country such as the UK, the broad strategic objective ${ }^{10}$ is to cut emissions by $80 \%$ between 1990 and 2050 . Policies are then designed to pursue those

\footnotetext{
${ }^{10}$ That objective was specified, prior to Paris COP21 in 2015, in relation to a global objective of holding temperature increases below $2 \circ \mathrm{C}$. "Well below $2 \mathrm{C}^{\circ}$ " the Paris objective requires stronger action. Net zero within 50 years or so (as in the Paris agreement) is now more appropriate, where net zero is more accurately described in the Paris language of balancing sources and sinks.
} 
strategic objectives within the context of some understanding of strategy for action based on the strategic objectives. The point I want to emphasise here is that the detail of policies cannot be set out without the context of an overall strategy. At one level this is another formulation of the familiar observation in economics, that the prices reflecting marginal costs or benefits cannot be described until we know roughly where we are planning to be. I do not want to discuss here the detail of the strategies that could emerge from some of the principles articulated below. My key point is simply that strategy is necessary to anchor policy specifics and for precision about policy.

One example will illustrate. The Stern-Stiglitz Commission (see report, May 2017) was asked to indicate ranges and paths of carbon prices which, appropriately combined with other policies could deliver on the Paris target. The strategy provided the context in which price policy could be developed. That price path is not some estimate of the evolution of social marginal damage, it is a price path that can guide change at the necessary scale and pace. And it has to take into account the need to induce rapid technical innovation as well as investment of the necessary type and scale.

A key principle for guiding strategy in the context of climate change must be the importance of integrating mitigation, adaptation and development. These three elements are sometimes described as alternatives or, in some sense in competition for priorities or resources. They should be seen as interwoven strands. There are many examples. Let me give just one. The SRI ${ }^{11}$ approach to rice involves different spacings and planting depths, and avoids the flooding of the paddy fields both elements in contrast to hitherto standard methods.. It saves on water and energy and thus constitutes more efficient development. It avoids the emission of methane from flooded fields, and is thus contributing to mitigation. And it is more robust to difficult weather conditions, in other words, more resilient; that is adaptation. Many more examples could be offered from energy, buildings, transport, and so on. It is thus a basic mistake to separate these three issues, whether in analysis or in funding or in organisation.

A further basic principle is the importance of credibility, clarity and coherence in policy. Government-induced policy risk is arguably the biggest threat to investment of any kind, be it sustainable or otherwise. Sometimes clear and strong legislation and institutions can contribute the necessary confidence behind strong investment. Examples could include the UK climate change legislation or the embodiment of climate targets in China's five-year plans.

In designing strategy we should recognise that it should give some account of the basic mix of instruments, including regulation and quantity criteria, prices and taxes, and public investment; and the kind of institutional arrangements which might enhance credibility.

\section{Market failures}

In Stern (2007), we described emissions of greenhouse gases as the greatest market failure the world has ever seen. This is because the consequences are so large and we are all

\footnotetext{
${ }^{11}$ System of root intensification.
} 
involved in both the causes and the effects. But a dynamic public economics in relation to climate change must recognise five further and crucial market failures. Whilst of crucial importance to climate change they are often of great relevance in many other public policy issues. The failures concern (i) research and development, (ii) imperfections in risk and capital markets (iii) networks, such as public transport grids, broadband and recycling, (iv) information available to producers and consumers, for example about the efficiency performance of capital equipment and the availability of different options, (v) co-benefits of action on climate, in particular concerning air, water and land pollution. All five involve powerful dynamic elements, as does the fundamental GHG externality.

There is much to say on all six of these market failures (the GHG externality plus the five listed above). Space prevents us from going in to great detail, but I hope that this brief description of what they are makes it clear that the policies for a sustainable dynamics of investment and consumption choices require attention to all six. It is simply not enough to fix the GHG externality through some carbon tax or price, or appropriate regulation and to assert that perfect and complete markets and vibrant entrepreneurship will take care of the rest. The GHG externality is indeed fundamental and is the first of our market failures, but we have to handle all six.

\section{Shaping investment}

Infrastructure investment is at the core of both achieving the Paris objectives and of delivering on the SDGs. Infrastructure investment is for the long term and generally involves a mix of public and private action and finance. Infrastructure investment in the world is a little over 3 trillion dollars a year now, and will likely rise to 6 or 7 , or more, in the next twenty years. How that investment takes place will, in large measure, determine whether we have any chance of holding to $2^{\circ} \mathrm{C}$. If we lock in high-carbon infrastructure over the next 20 years, then the chance of holding to $2^{\circ} \mathrm{C}$ will be gone, and indeed $3^{\circ} \mathrm{C}$ might be very difficult.

Policies and institutions as sketched above will be crucial to generating investment demand. There is plenty of saving in the world and many potential investment opportunities. But what is missing is the set of policies and institutions that can translate opportunity into real demand.

Further, investment demand has to be financed. Infrastructure projects can be very risky, particularly at the early stages. Good policies will reduce the risk, but cannot take it away. Development banks can play a major role in managing and reducing that risk still further. Their presence itself gives confidence about future policy. Further, they can bring a mix of instruments to the table, including equity, long-term loans and guarantees that can help get through these early stages. If that is successful, there is a great deal of private money that is available. They can be trusted convenors for drawing together partnerships and the blending of public and private finance.

In Bhattacharya et al (2016) we discuss, at some length, some quantitative and qualitative elements of the challenge of creating the necessary sustainable infrastructure and the possible policies and financial instruments and structures in the response to the challenge. 
This includes a large possible expansion of the role of multilateral development banks in fostering good policy and investment, and in managing risk and finance.

\section{The formation of international objectives}

The challenges of climate change are quintessentially those of a global public good. The driving force is the sum total, the overall concentrations, of GHGs in the atmosphere, irrespective of whether they come from London or Johannesburg, Chicago or Beijing, Munich or Delhi. Hence a coherent world policy requires common understanding and some shared objectives. A simple-minded economist's response to issues of collaboration would often be pessimistic with the statement that we have a "free-rider problem": let others make the reductions, we will not incur the costs ourselves. It is very interesting, indeed remarkable, that the world did get together to set an international target in Paris in December 2015 at COP21 of the UNFCCC and to set out basic mechanisms towards its achievement. It is a crucially important illustration of how people and communities can come to shared decisions and I comment briefly on how it came about and its lessons for dynamic public policy.

The Intergovernmental Panel on Climate Change (IPCC) has been working since 1988 to build a shared scientific understanding. It has had its difficulties and because it is a government-based group it tends to try to come to agreement on the state of science and analysis by finding bland statements and lowest common denominators. That can be problematic when extreme risks are of the essence. Nevertheless, it has helped to provide a broad foundation, with 30 years of substantial agreement over the scientific evidence on the risks. That is one key element of the foundations of the Paris agreement. And the evidence is that, as time goes by and still more evidence accumulates, the risks look evermore troubling.

A second key foundation of the Paris agreement was a growing understanding of the feasibility and attractiveness of low- or zero-carbon growth. The costs of energy alternatives to hydrocarbons have plummeted. We are seeing ever-stronger evidence of the costs and dangers of air, water and soil pollution from burning hydrocarbons. And we are understanding much better how to shape and manage our energy, transport, cities and infrastructure in much more efficient and less-polluting ways. We recognise much more clearly, how we can rehabilitate agricultural land, forests and ecosystems to our great benefit. And we see growing evidence of the costs of damaging our oceans.

This second area of understanding, on the feasibility and attractiveness of alternative paths to the high-carbon one, was critical to the success of COP21 in Paris. One contribution was the Better Growth, Better Climate report ${ }^{12}$ of 2014, but still more important was the direct experience of countries, both of the costs of pollution from burning hydrocarbons, and of the feasibility of different paths.

There were other important features to shaping the dynamics of understanding and the willingness to collaborate. One of these was the recognition that the absence of formal

\footnotetext{
12 This was from the Global Commission on Economy and Climate, which I co-chair, and its programme of work on the New Climate Economy.
} 
enforcement mechanisms and binding constraints could lead to greater ambition and achievement. Countries and peoples do take their commitments seriously, but are understandably reluctant to put themselves at risk of sanctions from others. They will agree to some degree of mutual scrutiny, but not necessarily to mutual punishment.

If we compare COP15 in 2009 in Copenhagen, which was fractious and had limited (but not negligible) achievement, with COP21 in 2015 in Paris, I think the above elements were crucial in driving change and agreement. From analysis and experience we can learn how to collaborate. That is a key lesson and challenge for a dynamic public economics. We learn, too, that the narrow-minded, self-interested model of human behaviour which many economists are so fond, is not always an accurate description of the attitudes of government and peoples to the management of major and global risks. People recognise and are concerned with the consequences of their actions for others. The depth of the understanding and the willingness to act will depend on context, language, communication and the reality of options; and on leadership. ${ }^{13}$ Understanding these processes should be a crucial element of a dynamic public economics.

\section{CONCLUSIONS}

The paper, inspired by conversations and collaboration with Tony Atkinson, and drawing on extensive experience of analysis and policy-making on climate change, has tried to argue the importance of building a new dynamic public economics. This is an economics that goes beyond simply dating goods by the time at which they appear. It goes beyond portraying growth using a simple growth model, which often embodies a strong focus on long-run steady states. It goes beyond the evaluation of policy via the marginal perturbations it might generate. It looks at the drivers, processes and pace of change. That is public economics as if time matters.

Many examples have been offered from climate change. We have to learn to understand, model and garner evidence on great risks, possibly existential for many. These could involve irreversibilities and destruction on a grand scale. We must recognise that the pace of change is intensely important. If path $A$ gets to low emissions 20 years later than path $B$, then the costs of the accumulated extra emissions could be immense. Pace really does matter.

Avoiding radical risk involves, in this example, radical and rapid change. We have to think clearly, but also quickly, how to manage the change and how public support can emerge, and indeed drive and shape change. That is true across countries as well as within. There are issues around equity, intratemporally as well as intertemporally, as Tony emphasised so strongly. Some of these, but not all, can be resolved by finding ways forward where many gain. Sharing of ideas and help with resources can be a vital part of this story. Those who are poor now will seek paths which are much cleaner and more sustainable than those of people who become richer earlier, both because there are now attractive options available, which can be inclusive as well as sustainable, and because they are concerned about

\footnotetext{
${ }^{13}$ For example, President Barack Obama and Xi Jinping announced their own country targets for emissions reductions, together in Beijing in November 2014, one year before Paris, COP21.
} 
consequences for succeeding generations. That is a process from which most can gain and which all should support. Finding ways to do this is part of a dynamic public economics.

I have tried to point to the dynamic public economics that we already have. There are indeed some valuable theoretical investigations available to us already. Examples offered above include the work of Aghion and others on public policy with dirty goods and endogenous growth, of Dixit and Pindyck on irreversibilties and investment around environmental action, and the work of Weitzman on extreme risk. At the same time, I have emphasised the severe limitations, indeed the misleading models and stories of current Integrated Assessment Models, which have been influential in the economics literature on climate change. It is time for a new generation of models.

We should not expect to get helpful results by building one grand model. I do not think that is a sensible way forward in the building of understanding and of good policy (although, of course, if some wish to try, that is their privilege. Good policy-makers and analysts learn how to blend the insights of a number of models and perspectives and draw on a broad range of empirical evidence. And I have emphasised the importance of the work of economic historians and political scientists, such as Schumpeter, Freeman, Crafts and Soskice, for whom processes of change, including the influence of and change in institutions, are of the essence in understanding how the world has changed, or could change.

Recognising the crucial questions around change and the type of perspective, theories and models that could be helpful in tackling them is the first step in formulating a research agenda for a dynamic public economics. A second step is to recognise what we already have as a basis on which to build. And in building a new dynamic public economics we must take care not to shoe-horn our modelling into familiar tools or workhorses which have limited capability to capture the issues at stake. Some details have been offered in the paper, particularly in relation to climate change, but there are many further fundamental examples. It is an exciting agenda.

Finally, I have tried, at the beginning of the paper, and at a number of places through the paper, to show the influence of Tony Atkinson's ideas. He challenged us all throughout the 50 years of his academic career to ask the hard and important questions and to bring decent values to our work. He insisted that we should identify and capture the crucial elements of the problem at hand and not try to force new and major issues into the existing, sometimes narrow, boxes and equipment with which we are most familiar. He was constantly taking on the big issues and exploring. He was a wonderful model, both as an economist and as a human being. Had he lived, he would have been very involved in building a dynamic public economics. His values, ideas, commitment and fine intelligence will surely inspire the next generation. 


\section{References}

Ablon, L. and Golay, A.A. 2017. "Wonks and geeks: examining commercial technology stakeholders' perceptions of and interactions with public policy", Science and Public Policy, 44 (4), $556-564$

Aghion, P., Dechezleprêtre,A., Hemous, D., Martin, R. and van Reenen, J., 2012. "Carbon taxes, path dependency and directed technical change: evidence from the auto industry". National Bureau of Economic Research Working Paper no 18596.

Aghion, P., Hepburn, C., Teytelblom, A., Zenghelis, D., 2014. "Path dependency, innovation and the economics of climate change". Grantham Research Institute on Climate Change and the Environment Policy Paper.

Akerlof, G.A., Shiller,R.J., 2009. Animal Spirits: How Human Psychology Drives the Economy, and Why It Matters for Global Capitalism. Princeton University Press: Princeton.

Arrow, K., Cropper, M., Gollier,C., Groom, B., Heal, G., Newell, W., Nordhaus, W., Pindyck, R., Pizer, W., Portney, P., Sterner, T., Tol, R.S.J., Weitzman, M., 2013. “Determining Benefits and Costs for Future Generations". Science. 341, 349 - 350.

Atkinson, A.B., 1969. Poverty in Britain and the Reform of Social Security. Cambridge University Press, Cambridge.

Atkinson, A.B., 1990. "Public economics and the economic public". Journal of Public Economics, 34, 225-248.

Atkinson, A.B. and Stern, N., 2017. "Tony Atkinson on Poverty, Inequality, and Public Policy: The Work and Life of a Great Economist", Annual Review of Economics, .9:1-20. www.annualreviews.org.

Atkinson, A.B., Stiglitz, J.E., 2015. Lectures on Public Economics. Princeton University Press, Princeton.

Auerbach, A.J., and L.J. Kotlikoff, 1987. Dynamic Fiscan Policy, Cambridge University Press, Cambridge.

Besley, T., and S. Coate, 1992. Workfare versus welfare: incentive arguments for work requirements in poverty-alleviation programmes", American Economic Review, 82:1, 249-261.

Besley, T., and S. Coate, 1995. "The design of income maintenance programmes", Review of Economic Studies, 62:2, 187-221.

Besley, T., O’Donnell, G., Stern, N., 2015. Reflections on Economics. British Academy: London.

Bhattacharya, A., Meltzer, J., Oppenheim, J., Qureshi, M.Z. and Stern, N., 2016. Delivering on Sustainable Infrastructure for Better Development and Better Climate. The Brookings Institution https://www.brookings.edu/research/driving-sustainable-developmentthrough-better-infrastructure-key-elements-of-a-transformation-program/.

Blanchard, O., 2018. "On the future of macroeconomic models", Oxford Review of Economic Policy, 34, 43-54. 
Cline, W.R., 1992. The economics of global warming. Peterson Institute Press, Washington.

Diamond, P., 1965. "The evaluation of infinite utility streams". Econometrica. 33, 170 - 177.

Diamond, P., Mirrlees, J., 1971. "Optimal Taxation and Public Production II: Tax Rules". American Economic Review. 61, 261 - 278.

Dixit A.K., Pindyck,R.S., 1994. Investment under Uncertainty. Princeton University Press, Princeton.

Drèze, J and Stern, N., 1990. "Policy reform, Shadow Prices and Market Prices". Journal of Public Economics. 42, 1 - 45.

Ellis, J., 1998. American Sphinx: The Character of Thomas Jefferson. Random House, New York.

Faulhaber, G.R. 2004. "Emerging Technologies and Public Policy: Lessons from the Internet", in: Day, G.S., and Schoemaker, P.J.H. eds. Wharton on Managing Emergent Technologies, 99-124. John Wiley \& Sons, Hoboken.

Guesnerie, R., 1977. "Financing public goods with commodity taxes: the tax reform viewpoint". Econometrica. 47,393-421.

Hayek, F., 1988. The fatal conceit: the errors of socialism. University of Chicago Press, Chicago.

Hirschman, A.O., 1958. The Strategy of Economic Development. Yale University Press, New Haven.

Hoppman, J, Huenteler, J., and Girod, B. 2014. "Compulsive policy-making: the evolution of the German feed-in tariff system for solar photovoltaic power", Research Policy, 43, $1422-1441$.

Kahneman, D., 2013. Thinking, Fast and Slow. Farrar, Straus and Giroux, New York.

Kaldor, N., 1940. "A Model of the Trade Cycle". Economic Journal. 50, 78-92.

Kaplow, L. and S. Shavell, 2013 "Fairness versus welfare: notes on the Pareto Principle, preferences and distributive justice", Journal of Legal Studies, 32, 331-362.

Koopmans, T.C., 1960. "Stationary Ordinal Utility and Impatience". Econometrica. 28, 287 309.

Krugman, P., 2000. "How complicated does the model have to be?', Oxford Review of Economic Policy, 16, 33-42.

Meade, J., 1955. Trade and Welfare. Oxford University Press, Oxford.

Minksy, H.P. 1982. Can "It" Happen Again? Essays on Instability and Finance. M.E. Sharpe, New York.

New Climate Economy. 2014. Better Growth, Better Climate.

http://2014.newclimateeconomy.report (accessed 06 September 2017). 
New Climate Economy. 2016. The Sustainable Infrastructure Imperative http://newclimateeconomy.report/2016/ (accessed 06 September 2017).

Nordhaus, W., 2013. "Integrated economic and climate modelling", in Dixon, P.B., Joregnson, D.W. (eds), Handbook of Computable General Equilibrium Modelling. Elsevier, pp. $1069-1131$.

Nordhaus, W.D. 1991. "A sketch of the economics of the greenhouse effect". American Economic Review. 81, 146 - 150.

Oreskes, G., Oreskes, N., 2017. “Assessing ExxonMobil's climate change communications. (1977-2014)". Environ Res Lett. 12, 1 - 18.

Oreskes, N., Conway, E.M., 2010. Merchants of Doubt: How a handful of scientists obscured the truth on issues from tobacco smoke to global warming. Bloomsbury Press, New York.

Pindyck, R. 2013. "Climate change policy: what do the models tell us?", Journal of Economic Literature, 51, 860-872.

Ramsey, F. 1928. "A mathematical theory of saving", Economic Journal, 38: pp.543-559.

Russell, B., 1961. History of Western Philosophy. Allen and Unwin, London.

Schumpeter,J.A., 1942. Capitalism, Socialism and Democracy. Harper and Row, New York.

Sen, A., 1999. Development as Freedom. Random House, New York.

Stern, N., 1991. "Public Policy and the economics of development". European Economic Review. 35, $241-271$.

Stern, N., 1992. Le Role de l'Etat dans le Developpement Economique, Conferences WalrasPareto Editions, Walras-Pareto, Lausanne.

Stern, N., 2007. The economics of climate change: The Stern Review. Cambridge University Press, Cambridge.

Stern, N., 2014. "Ethics, equity and the economics of climate change paper 1: science and philosophy". Economics and Philosophy. 30, 397-444.

Stern, N., 2015. Why are We Waiting? The logic, urgency and promise of tackling climate change. MIT Press, Cambridge.

Stern, N., Dethier, J.J., Rogers,F.H., 2005. Growth and Empowerment: Making Development Happen. MIT Press, Cambridge.

Stiglitz J.E. and Stern, N. (Commission Chairs), 2017. Report of the High-Level Commission on Carbon Pricing, Carbon Pricing Leadership Coalition. https://www.carbonpricingleadership.org/report-of-the-highlevel-commission-oncarbon-prices/.

Tol, R.S.J., 2012. "On the uncertainty about the total economic impact of climate change". Environmental Resource Economics. 53, 97 - 116.

United Nations Environment Programme, 2012. One Planet, How Many People? A Review of Earth's Carrying Capacity. 
https://na.unep.net/geas/archive/pdfs/geas_jun_12_carrying_capacity.pdf (accessed 06 September 2017).

Weitzman, M.L., 2011. "Fat tailed uncertainty in the economics of catastrophic climate change". Review of Environmental Economics and Policy. 5, 275 - 292. 